\title{
In situ hybridization of bat chromosomes with human (TTAGGG) probe, after previous digestion with Alu I
}

\author{
Karina de Cassia Faria ${ }^{1}$ and Eliana Morielle-Versute ${ }^{2}$ \\ ${ }^{1}$ Departamento de Biologia, IBILCE, UNESP, São José do Rio Preto, SP, Brazil. \\ ${ }^{2}$ Departamento de Zoologia e Botânica, IBILCE, UNESP, São José do Rio Preto, SP, Brazil.
}

\begin{abstract}
The purpose of this work was to verify the ability of the enzyme Alu I to cleave and/or remove satellite DNA sequences from heterochromatic regions in chromosomes of bats, by identifying the occurrence of modifications in the pattern of fluorescence in situ hybridization with telomeric DNA. The localization and fluorescence intensity of the telomeric DNA sites of the Alu-digested and undigested chromosomes of species Eumops glaucinus, Carollia perspicillata, and Platyrrhinus lineatus were analyzed. Telomeric sequences were detected at the termini of chromosomes of all three species, although, in C. perspicillata, the signals were very faint or absent in most chromosomes. This finding was interpreted as being due to a reduced number of copies of the telomeric repeat, resulting from extensive telomeric association and/or rearrangements undergone by the chromosomes of Carollia. Fluorescent signals were also observed in centromeric and pericentromeric regions in several two-arm chromosomes of E. glaucinus and C. perspicillata. In E. glaucinus and P. lineatus, some interstitial and terminal telomeric sites were observed to be in association with regions of constitutive heterochromatin and ribosomal DNA (NORs). After digestion, these telomeric sites showed a significant decrease in signal intensity, indicating that enzyme Alu I cleaves and/or removes part of the satellite DNA present in these regions. These results suggest that the telomeric sequence is a component of the heterochromatin, and that the C-band- positive regions of bat chromosomes have a different DNA composition.
\end{abstract}

Key words: AluI, FISH, Chiroptera, telomeric sites, DAPI.

Received: August 2, 2002; accepted: November 4, 2002.

\section{Introduction}

The telomeres of chromosomes are composed by specific tandem repeats of the DNA sequence (TTAGGG) that are conserved in all species of vertebrates (Meyne et al., 1989, 1990). This repeated sequence has been detected not only in telomeres, but also in interstitial and centromeric chromosomal regions, in a variety of vertebrate species; in almost all of them, it is coincident with positive C-bands (Meyne et al., 1989, 1990; Abuín et al., 1996; Vermeesch et al., 1996; Garagna et al., 1995; Ono and Yoshida 1997; Sharma and Sharma, 1998; Go et al., 2000; Pagnozzi et al., 2000). Although this association has not yet been clarified, there are suggestions that it might indicate that the sequence $\left(\mathrm{T}_{2} \mathrm{AG}_{3}\right)_{\mathrm{n}}$ is a component of the centromeric repeats (Metcalf et al., 1997, 1998). The presence of the sequence $\left(\mathrm{T}_{2} \mathrm{AG}_{3}\right)_{\mathrm{n}}$ in interstitial regions has been interpreted as a result of saltatory replications and insertions at intrachromosomal sites through the repair of

Send correspondence to E. Morielle-Versute. Depto. Zoologia e Botânica, Cristovão Colombo 2265, 15.054-000 São José do Rio Preto, SP, Brazil. E-mail: morielle@ zoo.ibilce.unesp.br. double-strained breaks occurred in the germline during evolution (Pathak et al., 1995, 1998; Azzalin et al., 2001; Faravelli et al., 2002). Despite the coincident localization of the telomeric repeat and heterochromatin, not all heterochromatic regions of bat chromosomes, nor of other vertebrate species, hybridize with telomeric DNA (Fontana et al., 1998; Gornung et al., 1998; Finato et al., 2000; Multani et al., 2001; Castiglia et al., 2002).

Several in situ digestion studies with restriction endonucleases (REs) have shown that heterochromatic regions in chromosomes of different species of vertebrates are constituted by different structural classes of heterochromatin. The REs induce structural alterations in metaphase chromosomes which could be related, at the cytological level, to specific structural characteristics of eukaryote chromosome bands, reflecting a distribution of different DNA sequences along the chromosomes (Fernandez et al., 1998; Garcia et al., 1999).

Restriction endonuclease Alu I cleaves alphoid DNA sequences of the heterochromatic centromeres of human chromosomes. These regions represent one of the highly 
repetitive sequence families localized in those areas, therefore this enzyme is able to cleave human chromosomal DNA, regardless of chromatin organization and the different structural classes of heterochromatin (Arn and Jabs, 1990; Nieddu et al., 1999). In this regard, it is noteworthy that macromolecules such as specific endonucleases have been employed for the investigation of the fine-structure organization of chromatin.

The purpose of this investigation was to verify the ability of Alu I to cleave and/or remove satellite DNA sequences from heterochromatic regions of bat chromosomes with heterochromatin in telomeric, pericentromeric and interstitial regions, and to identify the occurrence of any modification in the pattern of fluorescence in situ hybridization with a telomeric DNA probe, after chromosome digestion with Alu I.

\section{Material and methods}

\section{Chromosome preparations}

Cell preparations were obtained from primary fibroblast cultures initiated from lung biopsies, as described by Morielle-Versute and Varella-Garcia (1995), of two specimens of each Carollia perspicillata (CFC- 465, CFC- 531), Eumops glaucinus (CFC- 329, CFC - 383), and Platyrrhinus lineatus (CFC - 376, CFC-577). Mitotic chromosome spreads were prepared following mitotic arrest with colchicine $\left(4 \times 10^{-4 \mathrm{M}}\right)$ for $30 \mathrm{~min}$, hypotonic treatment ( $1 \%$ sodium citrate) for $30 \mathrm{~min}$, and fixation in 3:1 methanol: acetic acid (v/v).

\section{Alu I digestion of metaphase chromosomes}

Digestion of mitotic chromosomes was performed by the method described by Mezzanotte et al. (1983). Slides were aged for about a week at room temperature. Alu I (Gibco BRL) was used at a final concentration of $15 \mathrm{U} /$ slide, diluted in the enzyme buffer suggested by the manufacturer. The slides were kept in a moist chamber and incubated at $37{ }^{\circ} \mathrm{C}$ for four to six hours. Control experiments were carried out by incubation of fixed chromosomes for the same time and at the same temperature, with incubation buffer, but without the enzyme used for in situ digestion. After RE digestion, the slides were rinsed in deionised water and stained in 5\% Giemsa.

\section{Fluorescence in situ hybridization (FISH)}

The Alu I-digested and the undigested (control) slides were destained and then submitted to in situ hybridization with a telomeric DNA probe. For in situ hybridization, the digoxigenin-labelled deoxynucleotide oligomer (TTAG $\mathrm{GG})_{\mathrm{n}}$ was used as a probe (P5097-DG, Oncor - all telomeres). Slides were pretreated with RNAse $(0.1 \mu \mathrm{g} / \mathrm{mL})$ and pepsin $(0.008 \%)$, and denatured in $70 \%$ formamide/ $2 \mathrm{xSSC}, \mathrm{pH} 7.0$ at $72{ }^{\circ} \mathrm{C}$ for $2-3 \mathrm{~min}$. The probe was denatured in a water bath at $72{ }^{\circ} \mathrm{C}$ for $5 \mathrm{~min}$, quickly chilled on ice, centrifuged for $2 \mathrm{~s}$, and applied to selected areas of the slides ( $27 \mu \mathrm{L} /$ slides with $22 \times 50 \mathrm{~mm}$ coverslips). For hybridization, they were placed in a moist chamber for $16 \mathrm{~h}$ at $37^{\circ} \mathrm{C}$. Slides were then washed three times for five minutes each in $50 \%$ formamide/ $2 \mathrm{xSSC}$ and in $2 \mathrm{xSSC}$, at $37^{\circ} \mathrm{C}$. Finally, they were washed twice in $4 \mathrm{xSSC}, 0.05 \% \mathrm{v} / \mathrm{v}$ Tween 20, pH 7.0, at room temperature. Detection was performed with fluorescein-isothiocyanate (FITC) conjugated to anti-digoxigenin, and the signal was amplified with one layer of rabbit anti-sheep and fluorescein anti-rabbit antibodies (Oncor). Chromosomes were counterstained with propidium iodide (PI - $0.3 \mu \mathrm{g} / \mathrm{mL}$ ) and diamidino-2 phenylindole (DAPI) in fluorescence antifade solution $(0.5 \mu \mathrm{g} / \mathrm{mL})$. Analysis was performed with a Zeiss Axiophot fluorescence microscope with interference filter sets for FITC and Texas red. Metaphases were photographed using Kodak Ektachrome 400 film.

\section{Results}

In the FISH experiments with a telomeric probe, the chromosomes of E. glaucinus which had not been previously treated with the enzyme exhibited telomeric sequences at the termini of the chromosomes. They also displayed telomeric repeats in heterochromatic centromeric and pericentromeric regions on almost all two arms chromosomes (Figure $1 \mathrm{~A}$ ).

In C. perspicillata, all chromosomes, except the third small pair of autosomes and the $\mathrm{X}$, showed hybridization in the heterochromatic centromeric regions, evidenced by intense fluorescent signals. However, the interstitial heterochromatic block of the short arm of the largest chromosome (1), and the terminal blocks of the four subtelocentric autosomes and of the $\mathrm{X}$ did not hybridize with the telomeric probe (Figure 1B). Of further note is the fact that most of the chromosomal ends did not hybridize with the telomeric probe.

In $P$. lineatus, telomeric sequences were observed only at the termini of the chromosomes (Figure 1C).

In contrast with the controls, in which the chromosomes showed a homogeneous coloration after Giemsa staining, the chromosomes previously digested with Alu I exhibited patterns similar to that observed in C-bands (Figure $2 \mathrm{~A}-\mathrm{C}$ ). The chromosomes treated with Alu I and subsequently hybridized in situ with a telomeric probe displayed a lighter pattern, different from that observed in controls. In the three species analyzed, the fluorescence-labeled area appeared to be reduced, as compared to the control chromosomes, a finding that was more evident in the chromosomes of C. perspicillata and E. glaucinus (Figure 1D-F).

In Alu I-treated and then hybridized chromosomes, the DAPI-positive regions showed a bright fluorescent signal when compared to controls, especially in $C$. perspicillata (Figure 3). Furthermore, in the analyzed species, the brightness of the DAPI-positive regions was vari- 

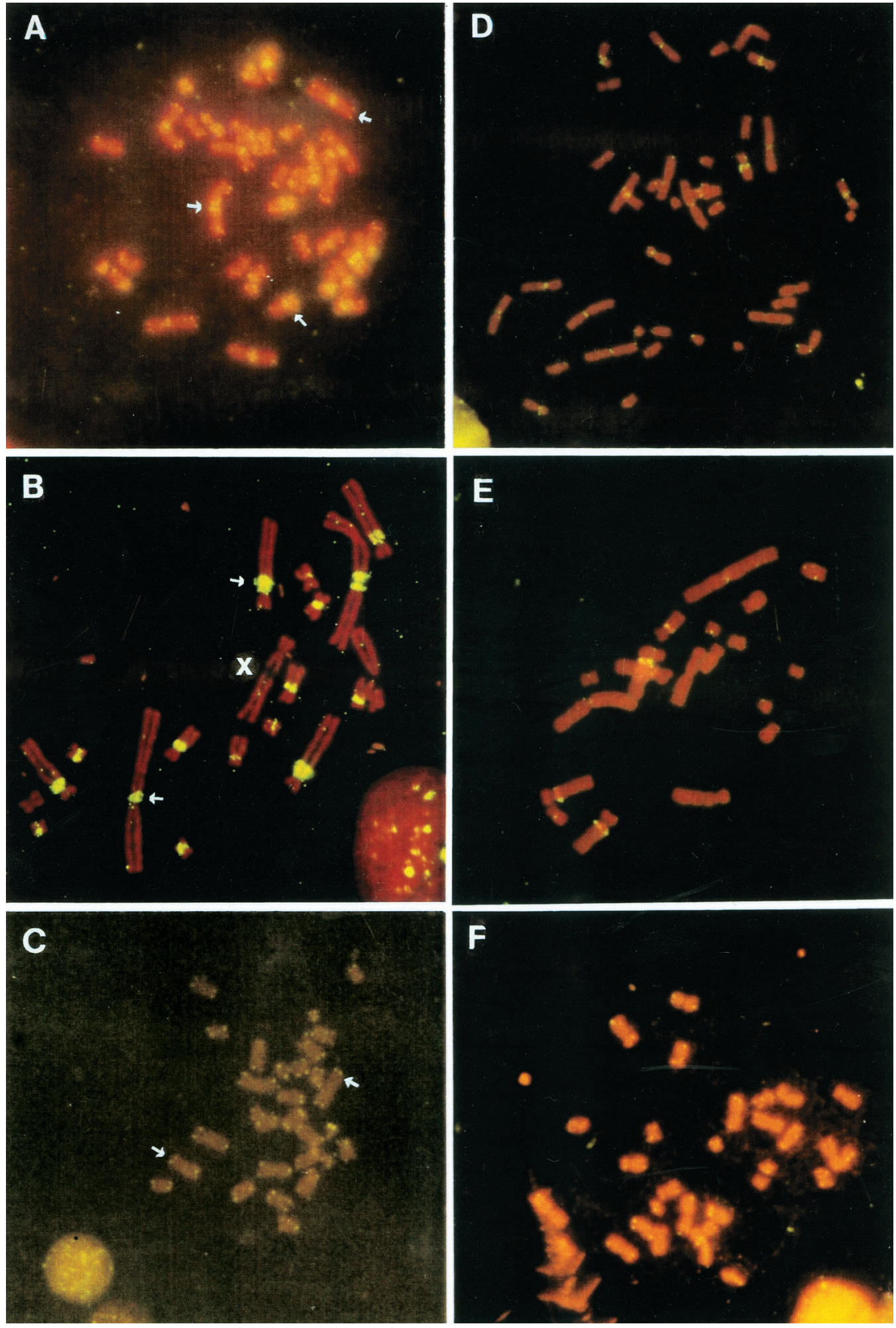

Figure 1 - Localization of the telomeric repeat (TTAGGG) in E. glaucinus (A and D), C. perspicillata (B and E) and P. lineatus (C and F): A - C: before digestion with Alu I, and D - F: after digestion with Alu I. Arrows indicate signals at the chromosome termini as well as at interstitial sites.

able between the heterochromatic regions (positive C-bands), and some of them were not DAPI-positive. Only these regions (DAPI-negative) were observed to have hybridized with the telomeric probe.
It is important to point out that, in both E. glaucinus and $P$. lineatus, the NORs occured in telomeric regions (Figure $2 \mathrm{E}, \mathrm{F}$ ) coincident with the telomeric sequence hybridization sites, whereas, in C. perspicillata, the NORs lo- 
cated at the secondary constriction of the $\mathrm{X}$ chromosome were not observed to have hybridized with the telomeric sequences (Figure 2D).

\section{Discussion}

The species E. glaucinus, C. perspicillata and $P$. lineatus are representative, respectively, of the three Chiroptera subfamilies Molossinae (of Molossidae), Caroliinae, and Stenodermatinae (of Phyllostomidae). All of them present large blocks of constitutive heterochromatin, distributed in terminal, centromeric and interstitial regions of the chromosomes.

Several studies have attempted to characterize the heterochromatic bands, showing that the areas of constitutive heterochromatin identified after C-banding correspond to satellite DNA regions (Pieczarka and Mattevi, 1998; Hennig, 1999; Ventura et al., 2001). Meyne et al. (1990) were able to demonstrate that in several vertebrate species interstitial C-bands present telomeric DNA within the satellite DNAs.

In the present work, the FISH results obtained with a telomeric probe in E. glaucinus and P. lineatus show that, similarly to other species of vertebrates and to E. glaucinus (Finato et al., 2000), the telomeric sequences occur at the termini of chromosomes. This finding was expected, since the repeat (TTAGGG) $)_{n}$ has been found to be the distinctive telomere sequence of vertebrates. However, in addition to those, all heterochromatic (pericentromeric and centromeric) regions of the E. glaucinus chromosomes hybridized with the telomeric probe. In $P$. lineatus, although the chromosomes presented heterochromatic blocks in terminal, pericentromeric and interstitial regions, the latter two were not observed to have hybridized with the telomeric probe. The same was observed in some chromosomes of $C$.

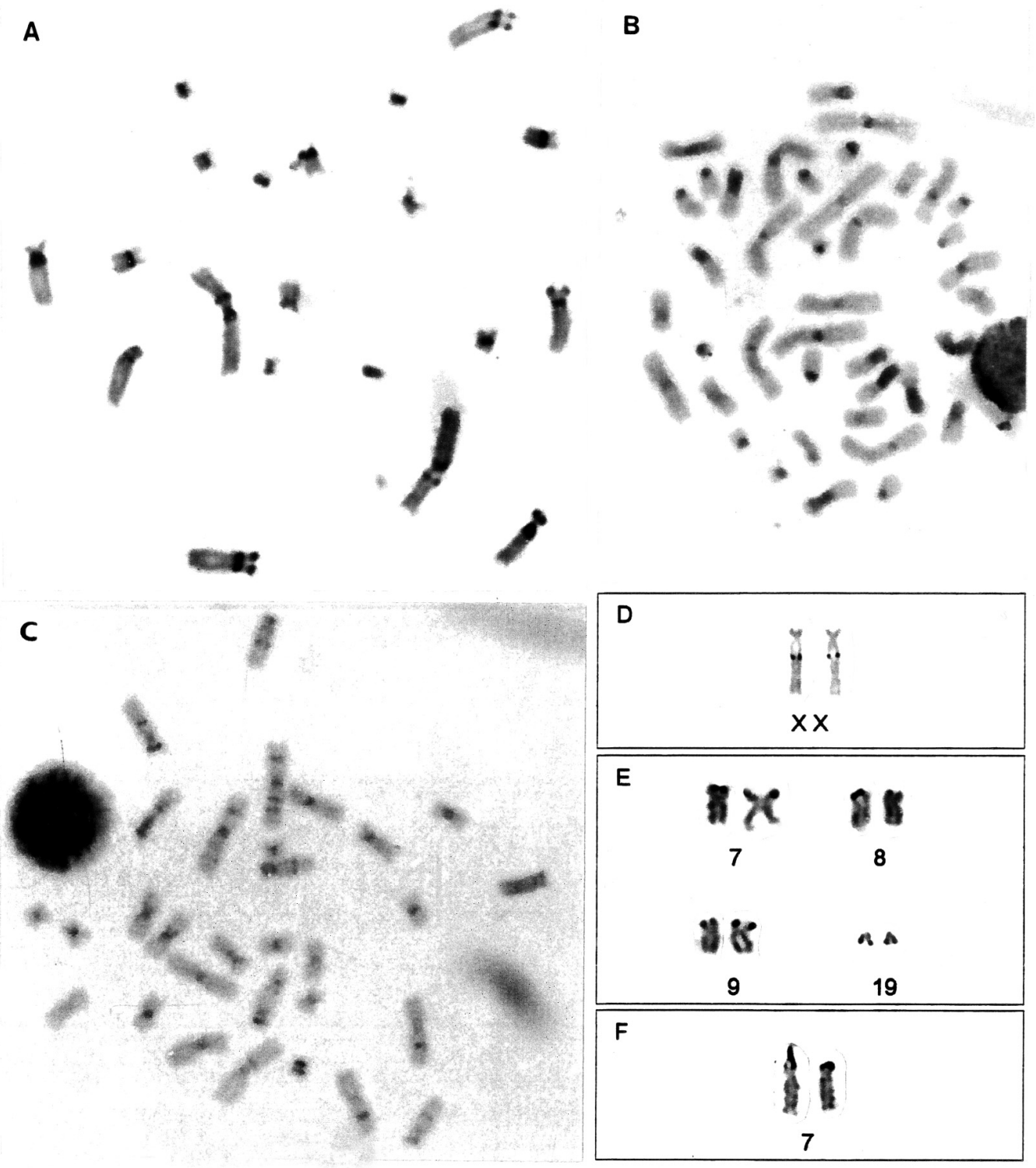

Figure 2 - Pattern of Alu I digestion and nucleolus organizer regions (NORs) in C. perspicillata (A and D), E. glaucinus (B and E), and P. lineatus (C and F). 

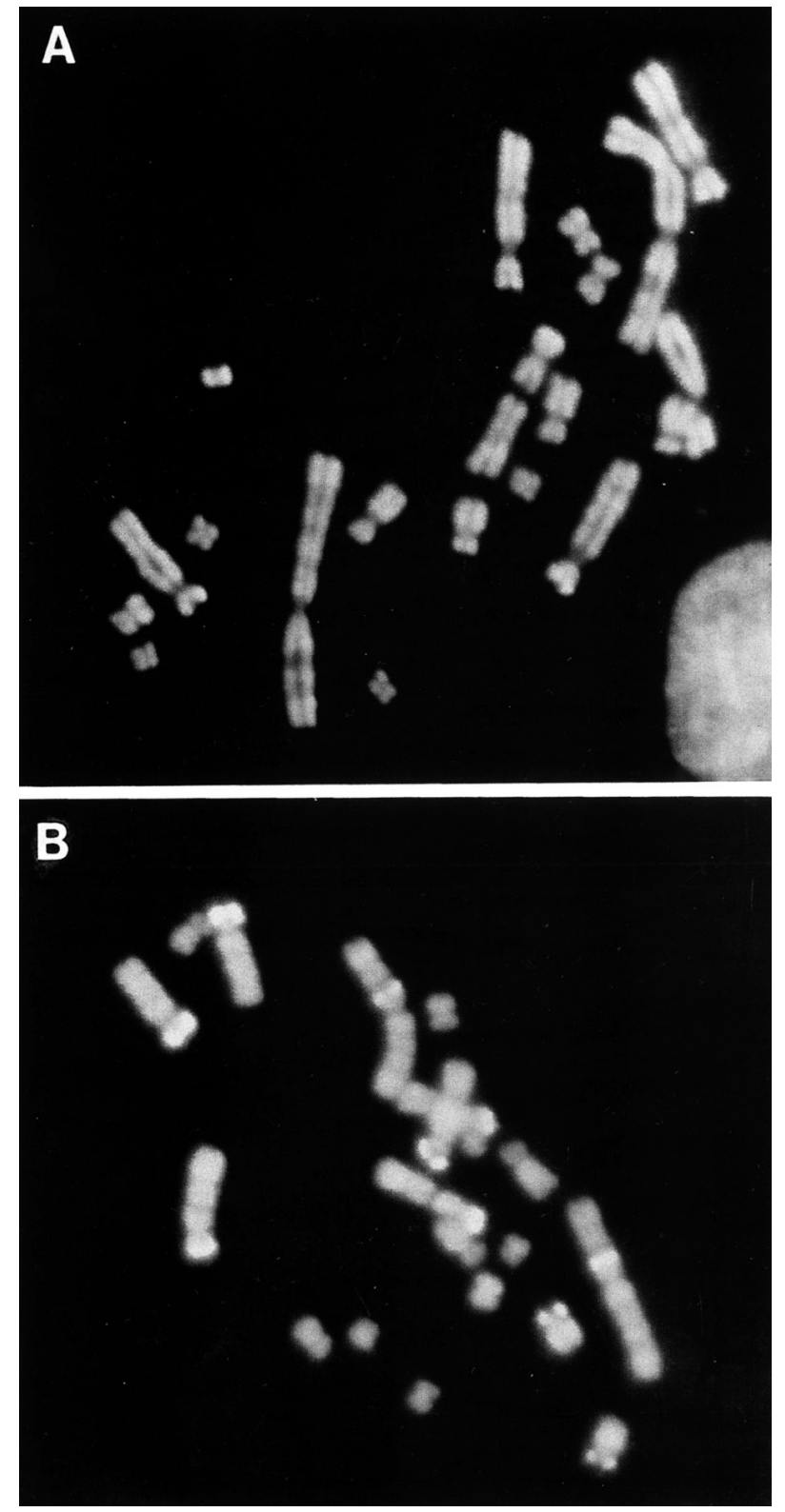

Figure 3 - Pattern of DAPI coloration in chromosomes of C. perspicillata, before (A) and after (B) Alu I digestion.

perspicillata, and had been previously reported in several other vertebrate species by Multani et al. (2001). Based on the determination and comparison of the telomeric DNA and heterochromatic sites of ten different species of vertebrates, these authors concluded that, although the heterochromatin bulk consists of telomeric DNA sequences, not all interstitial $\mathrm{C}$ bands are telomeric DNA, and not all regions which hybridize with telomeric DNA are C-bands.

An interesting fact was that, in C. perspicillata, most chromosome telomeres did not show any signal of hybridization with the telomeric probe, despite the intense hybridization observed in the centromeric and pericentromeric heterochromatic regions of several two arms chromosomes. Similar results were observed by Multani et al.
(2001), who interpreted the weak or absent terminal hybridization signals as being due to a reduced number of copies of the telomeric repeat, resulting from extensive telomeric association undergone by the chromosomes.

Meyne et al. (1990) suggest that the presence of non-telomeric (TTAGGG) ${ }_{\mathrm{n}}$ sequences might be related to the evolutionary status of the species. They state that primitive species usually have telomere-only patterns. Evolving species have several non-telomeric sites, and highly evolved species may have either non-telomeric sites or a telomere-only pattern. The results of our work support this idea. The karyotypes of E. glaucinus and C. perspicillata have many rearrangements, as compared to karyotypes considered primitive. Only some elements considered primitive are observed in the karyotype of E. glaucinus (Morielle-Versute et al., 1996), whereas in C. perspicillata no primitive karyotypes were identified (Stock, 1975). These observations and the FISH results of $C$. perspicillata indicate that other chromosomal mechanisms besides telomeric associations are likely to be involved where telomeric hybridization is absent.

The results observed in the chromosomes treated with Alu I, a pattern similar to the C-bands, were as expected for almost all REs including Alu I, confirming that they are able to produce bands similar to C-bands (Mezzanotte et al., 1983; Ferrucci et al., 1987; Wessman and Gripenberg, 1993; Balajee and Sharma, 1994; Mudry et al., 1994; Swarca et al., 2000).

Monitored studies of longitudinal chromosome differentiation have shown that in situ digestion with REs induces structural alterations in metaphase chromosomes and produces bands (RE-induced bands) that have been interpreted as being strictly dependent on the condensed chromatin conformation, on different classes of proteins, on their interaction with each other and/or with DNA. Thus, the results obtained are evidence that Alu I clevead the bat chromosomes differently. This was also evinced by the FISH pattern after digestion and DAPI staining, where both a reduction in the fluorescent hybridization signal (DAPInegative regions) and its opposite, a pronounced increase in the fluorescenct of DAPI-positive regions, were observed.

Nieddu et al. (1999) state that the alterations detected after digestion with REs could be related, at the cytological level, to specific structural characteristics of eukaryote chromosome bands, reflecting the distribution of different DNA sequences along the chromosomes. Taking into account that, in the analyzed species, Alu I proved able to cleave alphoid sequences in the DNA of fixed chromosomes, it is possible that the decrease in signal intensity was due to the capacity of Alu I to cleave the DNA of these regions differently, and remove part of it.

DAPI is a fluorochrome that binds to chromosome regions that are rich in A-T. As a rule, DAPI-positive regions coincide with C-bands. However, only DAPI-negative regions were observed to have hybridized with the 
telomeric probe. Similar results were reported by Hirai (2001), who analyzed four different hominoid species. In most of them, the chromosomal regions with C-band blocks coinciding with intense DAPI bands were negative for telomere-labeling signals. However, differently from our results, in Bonobo species (Pan paniscus), such areas (DAPI-positive and telomeric-negative) harbor nucleolus organizer regions (NORs). In the bat species E. glaucinus and $P$. lineatus, the NORs were coincident with telomeric hybridization sites, reinforcing the heterogeneity of satellite DNA. Considering the other possibilities to explain the association between constitutive heterochromatin and telomeric sequences and the conclusions from REs, the results of the present work indicate that, in some species of bats, the telomeric sequence is a component of the heterochromatin as well as the ribosomal DNA. The enzyme Alu I cleaved the bat chromosomes differently; in the analyzed species, the interstitial, terminal, and centromeric C-bands presented a different composition, reinforcing the view that they do not represent a homogeneous structural class of DNA, and that in bats the presence of non-telomeric sites, as well as alterations in the telomere-only pattern, are probably related to the evolutionary status of the species.

\section{Acknowledgments}

The authors wish to thank FAPESP (São Paulo State Foundation for the Support of Research) for financial support, and Dr. Cláudia M.C. Nigro for criticism and suggestions regarding the English manuscript.

\section{References}

Abuín M, Martínez P and Sánchez L (1996) Localization of the repetitive telomeric sequence $(\mathrm{TTAGGG})_{\mathrm{n}}$ in four salmonid species. Genome 39:1035-1038.

Arn PH and Jabs EW (1990) Characterization of human centromeric regions using restriction enzyme banding alphoid DNA and structural alterations. Mol Biol Medicine 7:371378 .

Azzalin CM, Nergadze SG and Giulotto E (2001) Human intrachromosomal telomeric-like repeats: sequence organization and mechanisms of origin. Chromosoma 110:75-82.

Balajee AS and Sharma T (1994) The chromosomal distribution of Mus musculus - like AT-rich heterochromatin in the $M$. dunni complex as revealed by Alu I digestion of metaphase chromosomes. Cytogenet Cell Genet 66:89-92.

Castiglia R, Gornung E and Corti M (2002) Cytogenetic analyses of chromosomal rearrangements in Mus minutoides/ musculoides from North-West Zambia through mapping of the telomeric sequence (TTAGGG) $)_{\mathrm{n}}$ and banding techniques. Chromosome Res 10:399-406.

Faravelli M, Azzalin CM, Bertoni L, Chernova O, Attolini C, Mondello C and Giulotto E (2002) Molecular organization of internal telomeric sequences in Chinese hamster chromosomes. Gene 283:11-16.

Fernandez JL, Goyanes VJ, Ramiro-Dias J and Gosalvez J (1998) Evidence of a differential organization of chromatin containing terminal or interstitial $(\mathrm{TTAGGG})_{(\mathrm{n})}$ repeats by in situ digestion with nucleases. Cytogenet Cell Genet 82:195-198.

Ferrucci L, Romano F and De Stefano GF (1987) The Alu I-induced bands in great apes and man: implication for heterochromatin characterization and satellite DNA distribution. Cytogenet Cell Genet 44:53-57.

Finato AO, Varella-Garcia M, Tajara EH, Taddei VA and Morielle-Versute E (2000) Intrachromosomal distribution of telomeric repeats in Eumops glaucinus and Eumops perotis (Molossidae, Chiroptera). Chromosome Res 8:563-569.

Fontana F, Tagliavini J, Congiu L, Lanfredi M, Chicca M, Laurent C and Rossi R (1998) Karyotypic characterization of the great sturgeon, Huso huso, by multiple staining techniques and fluorescent in situ hybridization. Marine Biol 132:495501.

Garagna S, Broccoli D, Redi CA, Searle JB, Cooke HJ and Capanna E (1995) Robertsonian metacentrics of the mouse lose telomeric sequences but retain some minor satellite DNA in the pericentromeric area. Chromosoma 103:685692.

Garcia F, Nogues C, Garcia M, Egozcue J and Ponsà M (1999) Characterization of constitutive heterochromatin in Cebus apella (Cebidae, Primates) and Pan troglodytes (Hominidae, Primates): comparison to human chromosomes. Am J Primatol 49:205-221.

Go Y, Rakotoarisoa G, Kawamoto Y, Randrianjafy AA, Koyama $\mathrm{N}$ and Hirai H (2000) PRINS analysis of the telomeric sequence in seven lemurs. Chromosome Res 8:57-65.

Gornung E, Gabrielli I and Sola L (1998) Localization of the (TTAGGG) $_{(\mathrm{n})}$ telomeric sequence in zebrafish chromosomes. Genome 41:136-138.

Hennig W (1999) Heterochromatin. Chromosoma 108:1-9.

Hirai H (2001) Relationship of telomere sequence and constitutive heterochromatin in the human and apes as detected by PRINS. Methods Cell Sci 23:29-35.

Metcalfe CJ, Eldridge MDB, McQuade LR and Johnston PG (1997) Mapping the distribution of the telomeric sequence $\left(\mathrm{T}_{2} \mathrm{AG}_{3}\right)_{\mathrm{n}}$ in rock-wallabies, Petrogale (Marsupialia: Macropodidae), by fluorescence in situ hybridization. I. The penicillata complex. Cytogenet Cell Genet 78:74-80.

Metcalfe CJ, Eldridge MDB, Toder R and Johnston PG (1998) Mapping the distribution of the telomeric sequence $\left(\mathrm{T}_{2} \mathrm{AG}_{3}\right)_{\mathrm{n}}$ in the Macropodoidea (Marsupialia), by fluorescence in situ hybridization. I. The swamp wallaby, Wallabia bicolor. Chromosome Res 6:603-610.

Meyne J, Ratliff RL and Moyzis RK (1989) Conservation of the human telomere sequence (TTAGGG) $)_{\mathrm{n}}$ among vertebrates. Proc Natl Acad Sci USA 86:7049-7053.

Meyne J, Baker RJ, Hobart HH, Hsu TC, Ryder O A, Ward O G, Wiley JE, Wurster-Hill DH, Yates TL and Moyzis RK. (1990) Distribution of non-telomeric sites of the (TTAGGG) $)_{\mathrm{n}}$ telomeric sequences in vertebrate chromosomes. Chromosoma 99: 3-10.

Mezzanotte R, Bianchi U, Vanni R and Ferrucci L (1983) Chromatin organization and restriction endonuclease activity on human metaphase chromosomes. Cytogenet Cell Genet 36: 562-566.

Morielle-Versute E and Varella-Garcia M (1995) A simple and fast procedure to grow bat fibroblasts from lung biopsies for cytogenetic studies. Brazilian J Genet 18:503-505. 
Morielle-Versute E, Varella-Garcia M and Taddei VA (1996) Karyotypic patterns of seven species of molossid bats (Molossidae, Chiroptera). Cytogenet Cell Genet 72:26-33.

Mudry MD, Ponsà M, Borrel A, Egozcue J and Garcia M (1994) Prometaphase chromosomes of the howler monkey (Alouatta caraya): G, C, NOR and Restriction Enzyme (Res) banding. Am J Primatol 33:121-132.

Multani AS, Ozen M, Furlong CL, Zhao Y-J, Hsu TC and Pathak S (2001) Heterochromatin and interstitial telomeric DNA homology. Chromosoma 110:214-220.

Nieddu M, Rossino R, Pichiri G, Rocchi M, Setzu MD and Mezzanotte R (1999) The efficiency of in situ hybridization on human chromosomes with alphoid DNAs enhanced by previous digestion with Alu I and Taq I. Chromosome Res 7:593-602.

Ono T and Yoshida MC (1997) Differences in the chromosomal distribution of telomeric (TTAGGG) $)_{\mathrm{n}}$ sequences in two species of the vespertilionid bats. Chromosome Res 5:203-212.

Pagnozzi JM, Silva MJD and Yonenaga-Yassuda Y (2000) Intraspecific variation in the distribution of interstitial telomeric (TTAGGG) $_{(\mathrm{n})}$ sequences in Micoureus demerarae (Marsupialia: Didelphidae). Chromosome Res 8:585-591.

Pathak S (1995) Centromere or telomere: who is the boss? Anticancer Res. 15:2549-2550.

Pathak S, Dolhonde JÁ and Multani AS (1998) Amplification of telomeric DNA and the extent of karyotypic evolution. Cytobios 93:141-146.
Pieczarka JC and Mattevi MS (1998) Heterocromatina constitutiva. Sociedade Brasileira de Genética. Série Monografias, n. 7, Ribeirão Preto, São Paulo, 248 pp.

Sharma GG and Sharma T (1998) Unusual chromosomal organization of telomeric sequences and expeditious karyotypic differentiation in the recently evolved Mus terricolor complex. Cytogenet Cell Genet 80:204-208.

Stock AD (1975) Chromosome banding pattern homology and its phylogenetic implication in the bat genera Carollia and Choeroniscus. Cytogenet Cell Genet 14:34-41.

Swarca AC, Giuliano-Caetano L and Dias AL (2000) Analyses of nucleolus organizer regions and heterochromatin of Pimelodus maculatus (Pisces, Pimelodidae). Genetica 110:97-100.

Ventura M, Boniotto M, Cardone MF, Fulizio L, Archiadiacono N, Rocchi M and Crovella S (2001) Characterization of a highly repeated DNA sequence family in five species of the genus Eulemur. Gene 275:305-310.

Vermeesch JR, De Meurichy W, Van Den Berghe H, Marynen P and Petit $P$ (1996) Differences in the distribution and nature of the interstitial telomeric (TTAGGG) $)_{\mathrm{n}}$ sequences in the chromosomes of the Giraffidae, okapi (Okapia johnstoni), and giraffe (Giraffa camelopardalis): evidence for ancestral telomeres at the okapi polymorphic rob $(4 ; 26)$ fusion site. Cytogenet Cell Genet 72:310-315.

Wessman M and Gripenberg U (1993) Restriction endonuclease staining profiles in the C-heterochromatin of Cervidae. I. The autosomes. Hereditas 118:243-249. 